\title{
MEDIA PEMBELAJARAN KAMUS BAHASA LATIN BERBASIS ANDROID
}

\author{
Al Amri, Sumitro Sarkum, Iwan Purnama \\ Akademi Manajemen Informatika Komputer Labuhan Batu \\ Jl. SM Raja No.126 Km.3.5 Aek Tapa, Rantauprapat \\ amrivanseri@gmail.com, sumitro.ulb@gmail.com, iwanpurnama2014@gmail.com
}

\begin{abstract}
Abstrak - Kamus bahasa latin merupakan sebuah media pembelajaran yang dapat meberikan kemudahan bagi para guru dan siswa di SMK AL-AZIZ. Fenomena yang terjadi adalah siswa-siswi di kelas memiliki kendala dengan bahasa latin tumbuh-tumbuhan untuk menyelesaikan tugas yang diberikan guru dalam memenuhi iuran pembelajaran yang sangat dibutuhkan dalam proses pembelajaran pada mata pelajaran IPA. Aplikasi ini dirancang menggunakan eclipse, Metode Waterfall, UML, dan database SQLite. Perancangan aplikasi ini diharapkan dapat bermanfaat bagi para siswa, guru, bahkan masyarakat umum.
\end{abstract}

\section{Kata Kunci- Android, Bahasa Latin, Kamus}

\begin{abstract}
The Latin Dictionary is a learning medium that can give ease to teachers and students at SMK ALAZIZ. The phenomenon that occurs is the students in the class have constraints with the Latin language plants to complete the task given by teachers in fulfilling the contribution of learning that is needed in the process of learning on science subjects. This app is designed using eclipse, Waterfall Methods, UML, and SQLite databases. The design of this application is expected to be useful for students, teachers, even the general public.
\end{abstract}

Keywords: Android, Latin, Dictionary

\section{PENDAHULUAN}

Perkembangan Teknologi Informasi Dan Dunia Hiburan Semakin Pesat,Sehingga Anak-Anak Kita Lebih Suka Melihat Sinetron, Film, Main Game, Internet Yang Akan Menjadi Guru Mereka Daripada Mendengarkan Pelajaran Guru Di Kelas. Oleh Karena Itu Guru Zaman Sekarang Dituntut Untuk Menciptakan Pembelajaran Yang Menarik Sekaligus Menghibur Agar Tidak Kalah Dengan Teknologi Informasi Dan Dunia Hiburan Yang Semakin Canggih. Panduan Kurikulum 2013 Guru Ditugaskan Untuk Membuat Materi Pembelajaran Semenarik Mungkin Dengan Melibatkan Media Elektronik Yang Digunakan Untuk Siswa Agar Lebih Fokus Dalam Kegiatan Proses Belajar.

Berdasarkan Kurikulum Tersebut Maka Pembelajaran Yang Diterapkan Pada Sekolah Masing-Masing Sesuai Dengan Kurikulum 2013. Sedangkan Fenomena Yang Terjadi Adalah Siswa-Siswi Di Kelas Memiliki Kendala Dengan Bahasa Latin Tumbuh-Tumbuhan Untuk Menyelesaikan Tugas Yang Diberikan Guru Dalam Memenuhi Iuran Pembelajaran Yang Sangat Dibutuhkan Dalam Proses Pembelajaran Baik Tingkat Smp,Sma/Smk Pada Mata Pelajaran IPA.

\section{TINJAUAN PUSTAKA}

A. Pengertian Bahasa, Bahasa Latin, Kamus

Bahasa Merupakan Hal Yang Sangat Penting Dalam Kehidupan Masyarakat. Sedangkan Alat Yang Paling Efektif Untuk Keperluan Itu Adalah Bahasa [1]. Bahasa Latin Adalah Sebuah Bahasa Italik Yang Berasal Dari Latium, Sebuah Daerah Di Italia Sekeliling Kota Roma Yang Termasuk Dalam Rumpun Indo Eropa. Bahasa Ini Menjadi Penting Karena
Munculnya Kekaisaran Romawi Dimana Bahasa Latin Adalah Bahasa Resminya [2]. Kamus Adalah Sebagai Media Pembantu Pencarian Kata-Kata Diharapkan Dapat Digunakan Semudah Dan Sepraktis Mungkin. Seorang Pengguna Membutuhkan Pencarian Kata Yang Dapat Membantu Mengartikan Kata-Kata Dari Informasi Yang Diinginkannya [3].

\section{B. Pengertian Android, Database, Database Sqlite}

Android Adalah Sistem Operasi Untuk Perangkat Mobile Yang Pengembangannya Dipimpin Oleh Google. Androidd Menyediakan Platform Yang Terbuka Bagi Mereka. Saat Ini Sudah Banyak Vendor-Vendor Smartphone Yang Memproduksi Smartphone Berbasis Android Seperti Samsung, Sony, $L g$, Dan Lain-Lain. Tidak Hanya Menjadi Sistem Operasi Di Smartphone, Saat Ini Android Menjadi Pesaing Utama Dari Apple Pada Sistem Operasi Tablet Dan Pc [4]. Database Adalah Struktur Penyimpanan Data. Database Juga Merupakan Kumpulan Dari Data Yang Saling Berhubungan Satu Dengan Yang Lainnya, Tersimpan Diperangkat Keras Komputer Dan Digunakan Perangkat Lunak Untuk Memanipulasikan [5].

Suatu Library Yang Menerapkan Mesin Database Self Contained, Serverless, Zero- Configuration, Dan Transactional. Self-Contained Berati Sqlite Membutuhkan Sedikit Sekali Dukungan Dari Library Eksternal Atau Sistem Operasi. Serverless Berati Sqlite Dalam Mengakses Database Baik Itu Read Atau Write Dapat Secara Langsung Dari File Database Tanpa Melalui Proses Server Dan Tidak Mendukung Pengaksesan Secara Remote (Artinya Database Sqlite Bisa Dikendalikan Dari Jarak Jauh Dengan Adanya Jaringan Komputer ("Computer Network") [6]. 


\section{Metode Waterfall}

Metode Waterfall Adalah Suatu Proses Pengembangan Perangkat Lunak Yang Berurutan, Di Mana Proses Pengerjaannya Terus Mengalir Dari Atas Ke Bawah (Seperti Air Terjun) Melewati Fase-Fase Requirements (Analisis Kebutuhan), Design (Perancangan Dan Pemodelan), Implementation (Penerapan), Verification (Pengujian), Dan Maintenance (Pemeliharaan) [7].

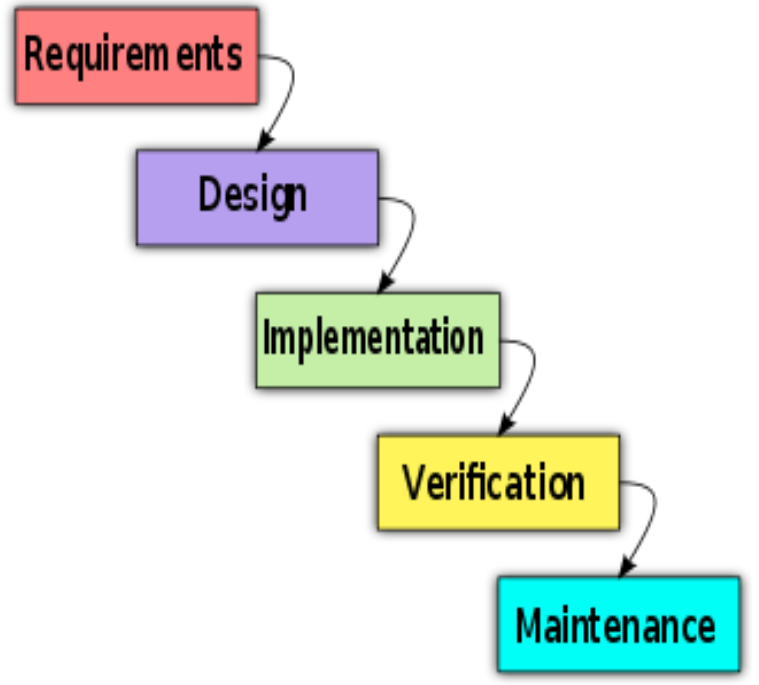

Gbr 1. Metode Waterfall

Fase-fase dalam Model Waterfall adalah sebagai berikut :

1. Requirement (analisis kebutuhan).

Dalam langakah ini merupakan analisa terhadap kebutuhan sistem. Pengumpulan data dalam tahap ini bisa melakukan sebuah penelitian, wawancara atau studi literatur. Seseorang peneliti akan menggali informasi sebanyak banyaknya dari pengguna sehingga akan tercipta sebuah aplikasi / program yang bisa melakukan tugas-tugas yang diinginkan oleh pengguna tersebut.

2. Design (Disain / Rancangan)

Proses Design akan menterjemahkan syarat kebutuhan ke sebuah perancangan perangkat lunak yang dapat diperkirakan sebelum diimplementasikan. Proses ini berfokus pada Detail Prosedural (flowchart \& Diagram), arsitektur perangkat lunak, representasi interface.

3. Implementation (Penerapan)

Tahapan inilah yang merupakan tahapan secara nyata dalam mengerjakan suatu sistem. Dalam artian penggunaan komputer akan dimaksimalkan dalam tahapan ini. Yaitu tahapan dimana keseluruhan desain diubah menjadi kode-kode program. kode program yang dihasilkan masih berupa modulmodul yang selanjutnya

akan di integrasikan menjadi sistem yang lengkap untuk meyakinkan bahwa persyaratan perangkat lunak telah dipenuhi. 4. Verification (Integrasi \& pengetesan)
Tahapan ini bisa jadi dikatakan sebagai final dalam pr oses pembuatan sebuah sistem. Yaitu tahap verifikasi oleh pengguna. Pengguna akan menguji apakah aplikasi yang telah dibuat tersebut telah sesuai dengan keinginan pengguna. Tahapan ini adalah final dalam pembuatan program, tapi bukan pada metode pengembangan program.

5. Maintenance (Pemeliharaan)

Tahap akhir pengembangan sistem pada model Waterfall adalah pemeliharaan yang termasuk diantaranya instalasi dan proses perbaikan sistem sesuai dengan keinginan pengguna atau yang sesuai dengan kontrak kerja.

\section{METODE PENELITIAN}

\section{A. Metode Pengumpulan Data}

Metode penelitian yang digunakan dalam penyusunan Tugas Akhir ini adalah dengan menggunakan metode deskriktif yaitu penelitina yang dilakukan berdasarkan data yang sebenarnya dengan membandingkan teori kemudian mengambil kesimpulan.

Metode pengumpulan data adalah satu cara yang digunakan untuk mengumpulkan data dari suatu sistem. Guna memperoleh data yang diperlukan dalam penyusunan Tugas Akhir ini, penulis menggunakan metode pengumpulan data. Adapun metode pengumpulan data yang dilakukan oleh penulis untuk menyusun Tugas Akhir ini adalah sebagai berikut:

1. Metode Penelitian Lapangan (Field Research)

Suatu metode penelitian yang digunakan secara langsung, pada saat penulis melakukan riset untuk mengumpulkan data. Pada metode ini menggunakan teknik-teknik sebagai berikut:

1) Wawancara (Interview)

Yaitu melakukan tanya jawab langsung tentang poinpoin tertentu kepada guru maupun siswa sehingga dapat menghasilkan data dan informasi yang dibutuhkan. Adapun alat yang digunakan adalah alat tulis seperti pena, pensil, dan buku.

2) Pengamatan (Observation)

Yaitu suatu hal atau proses penelitian dan pengamatan yang dilakukan secara langsung dengan tujuan ingin mengetahui sistem yang sedang berjalan dengan mengamati aliran-aliran informasi data.

\section{Metode Belajar}

Yaitu penulis melakukan penggalian data dengan cara mengamati proses belajar mengajar di dalam kelas ketika seorang guru memberikan tugas kepada siswa yang berhubungan mata pelajaran Ilmu Pengetahuan Alam (IPA), serta tulisan-tulisan ilmiah yang berkaitan dengan Tugas Akhir ini, terutama yang berhubungan dengan masalah belajar ketika guru memberikan tugas mata pelajaran Ilmu Pengetahuan Alam (IPA) kepada siswa.

\section{B. Metode Perancangan Sistem}

1. Tahap perencanaan sistem

Tahap perencanaan adalah tahap awal pengembangan sistem yang mendefinisikan perkiraan kebutuhan sumber daya seperti 
perangkat fisik, manusia, metode (teknik dan operasi), dan anggaran yang sifatnya masih umum (belum rinci).

2. Analisa kebutuhan sistem

Tahap analisa kebutuhan sistem merupakan tahap penelitian atas sistem yang telah ada dengan tujuan merancang sistem yang baru atau diperbaharui. Tahap ini merupakan tahap kritis dan sangat penting karena akan menentukan berhasil tidaknya sistem yang akan dibangun atau dikembangkan.

3. Perancangan sistem

Tujuan pada tahap perancangan sistem adalah untuk memenuhi kebutuhan kepada para pemakai, serta memberikan gambaran yang jelas dan rancang bangun yang lengkap kepada pemrogram komputer dan ahli teknik lain yang terlibat.

4. Implementasi

Tahap implementasi atau penerapan adalah tahap dimana desain sistem dibentuk menjadi suatu kode (program) yang siap untuk dioperasikan.

5. Manajemen dan pemeliharaan

Tahap pemeliharaan merupakan tahap yang dilakukan setelah implementasi, yang meliputi pemakaian atau penggunaan, audit, penjagaan, perbaikan, dan peningkatan sistem.

\section{HASIL DAN PEMBAHASAN}

A. Hasil

Pada tahap ini akan dijelaskan hasil bagian dari semua fungsi yang ada pada aplikasi kamus nama latin tumbuhtumbuhan seperti tampilan masukan data, nama latin, bahasa inggris. hasil nama latin dan bahasa inggris benar atau salah dan tampilan keluar setelah diterjemahkan oleh user. jika data nama tumbuh-tumbuhan yang ingin di inputkan salah, maka pada tampilan aplikasi kamus latin memberikan pesan "Maaf kata tidak ditemukan" yang akan dijelaskan pada tahapan-tahapan dibawah ini. Agar user dapat memahami secara detail cara menjalankan aplikasi kamus nama latin tumbuh-tumbuhan.

\section{B. Tampilan Icon}

Tampilan ini akan menampilkan aplikasi kamus latin di dalam menu android secara offline dan tampilan icon aplikasi kamus latin berbasis android sebagai berikut:

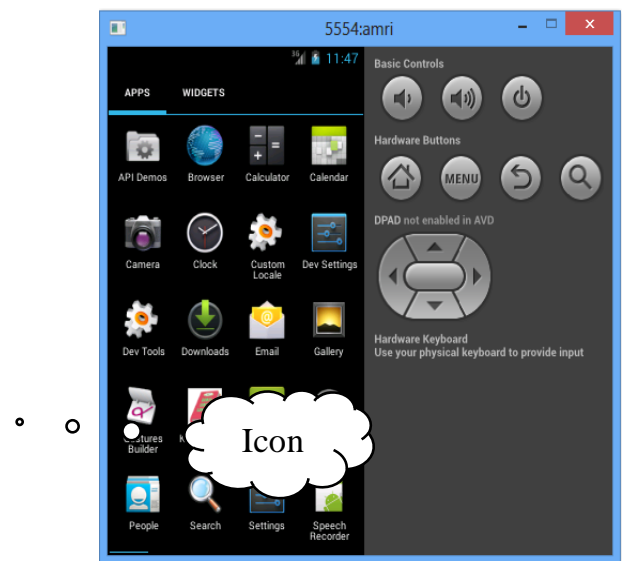

Gbr 2. Tampilan Icon
Pada gambar 2 merupakan tampilan icon, ditampilan ini user dapat melihat icon aplikasi Kamus Latin berbasis android sebelum masuk ke aplikasi.

\section{Tampilan Aplikasi Kamus Latin}

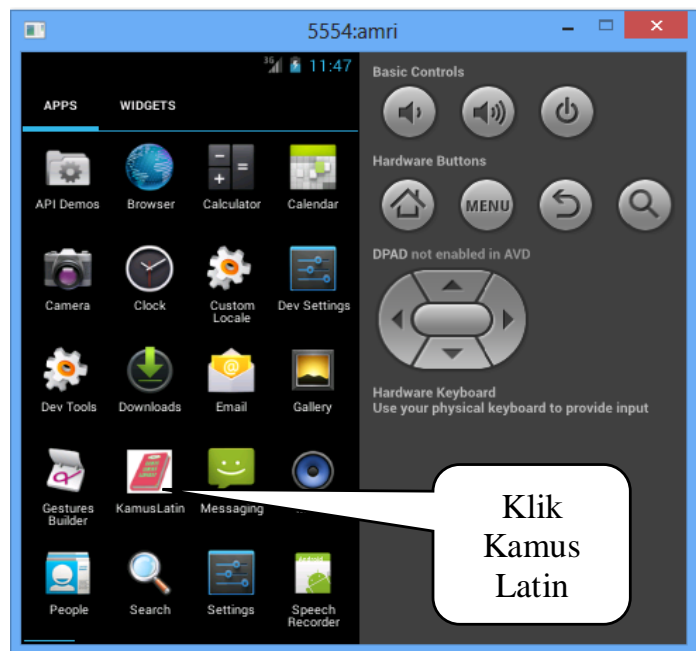

Gbr 3. Tampilan Aplikasi Kamus Latin

Pada gambar 3 merupakan tampilan aplikasi kamus latin, disini user harus mengklik icon aplikasi kamus latin berbasis android untuk masuk ke tampilan berikutnya.

\section{Tampilan Input}

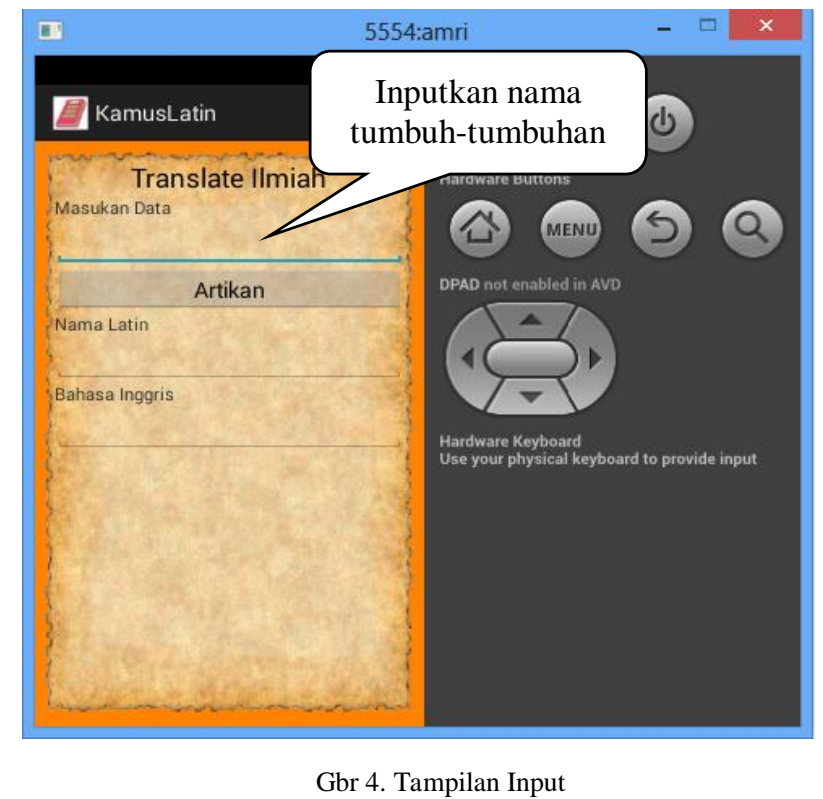

Pada gambar 4 di atas adalah penginputan nama tumbuhtumbuhan pada aplikasi kamus latin berbasis android dimana penginputan nama tumbuh-tumbuhan ini bertujuan agar 
mengetahui user yang menginputkan nama latin tersebut. Contoh penginputan nama tumbuh-tumbuhan "Anggrek".

\section{E. Tampilan Proses}

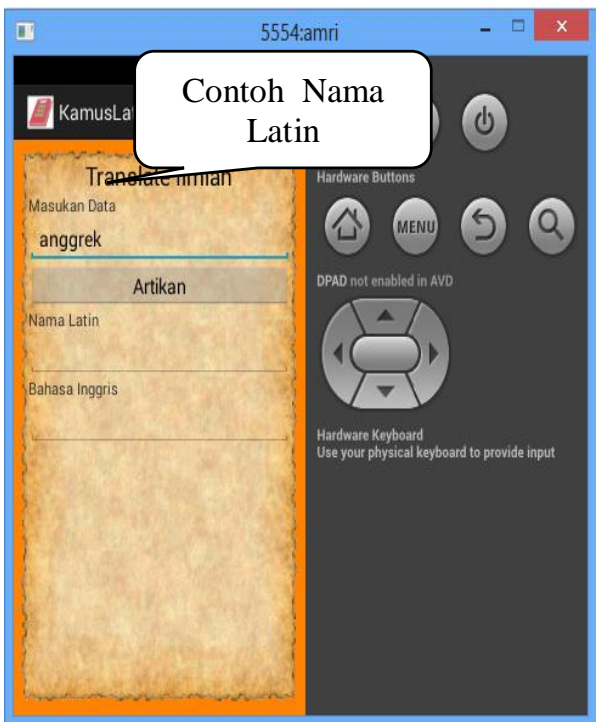

Gbr 5. Tampilan Proses

Pada gambar 5 Dimana user akan menginputkan nama tumbuh-tumbuhan pada aplikasi kamus latin berbasis android. kamus latin tumbuh-tumbuhan tersebut terdiri dari nama latin dan bahasa inggris dimana nama latin dan bahasa inggris tersebut yang berisi tentang terjemahan nama latin tumbuhtumbuhan dan bahasa inggris. Contoh nama tumbuh-tumbuhan.

\section{F. Tampilan Hasil}

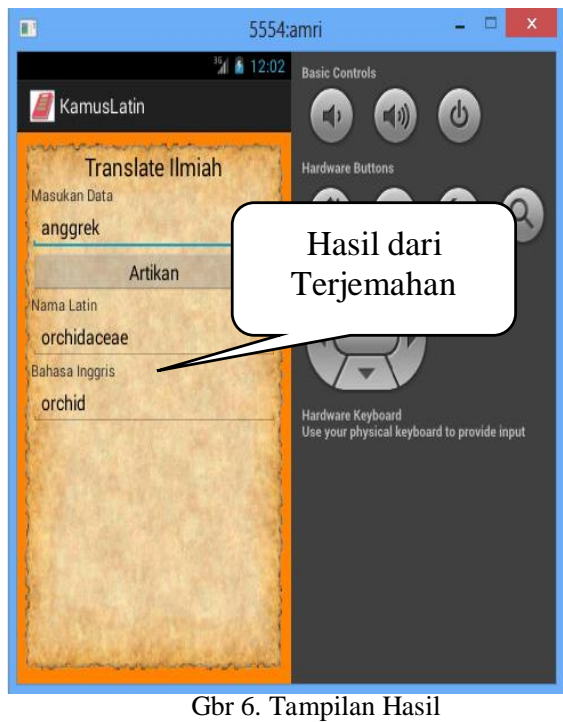

Pada tampilan 6 merupakan tampilan hasil. Disini user dapat melihat tampilan terjemahan yang diperoleh. Jika nama tumbuh-tumbuhan yang di inputkan benar user akan melihat hasil terjemahan, jika jawaban yang di inputkan salah maka user akan melihat hasil terjemahan "Maaf kata tidak ditemukan". Apabila user ingin melanjutkan kamus latin kembali bisa menginputkan data ulang dan jika tidak user dapat mengklik tombol keluar.

\section{A. Kesimpulan}

\section{KESIMPULAN DAN SARAN}

Berdasarkan hasil implementasi aplikasi kamus nama latin tumbuh-tumbuhan, maka dapat disimpulkan bahwa :

1. Aplikasi kamus nama latin tumbuh-tumbuhan berbasis android dapat dimanfaatkan siswa maupun masyarakat umum dalam melakukan pencarian katakata nama latin tumbuh-tumbuhan yang menggunakan nama latin dan bahasa inggris menggunakan smartphone berbasis android.

2. Aplikasi kamus nama latin tumbuh-tumbuhan berbasis android dapat diimplementasikan pada sistem operasi android versi 2.2 sampai dengan 8.0 (Oreo).

3. Pembuatan aplikasi kamus nama latin tumbuhtumbuhan dengan menggunakan Eclipse dan menggunakan database SQLite lebih mudah dalam hal perancangan maupun untuk hasil akhir (output) dan lebih mudah dimengerti oleh user karena menggunakan bahasa pemrograman Java berbasis android.

\section{B. Saran}

Dalam hal ini, penulis memberikan saran yang kiranya dapat bermanfaat untuk kemajuan Aplikasi kamus nama latin tumbuh-tumbuhan, yaitu :

1. Aplikasi kamus nama latin tumbuh-tumbuhan masih sangat sederhana sehingga perlu adanya penambahan fitur-fitur yang ada di aplikasi terlihat menarik.

2. Aplikasi kamus nama latin tumbuh-tumbuhan memiliki database yang masih sedikit sehingga diperlukan penambahan kata dalam aplikasi.

Diharapkan memberikan fungsi suara agar pengguna dapat belajar berbicara bahasa latin dan bahasa inggris dengan benar.

\section{REFERENSI}

[1] Yuliana, R., Rohmadi, M. and Suhita, R. (2013) 'Daya Pragmatik Tindak Tutur Guru Dalam Pembelajaran Bahasa Indonesia Pada Siswa Sekolah Menengah Pertama', Jurnal Penelitian Bahasa,Sastra Indonesia dan Pengajarannya, 2(1), pp. 1-14.

[2] Ruslan, N. I., Pramono, B. and Subardin (2016) 'APLIKASI KAMUS BAHASA LATIN HEWAN DAN TUMBUHAN MENGGUNAKAN METODE BRUTE FORCE DAN FITUR AUTOCOMPLETE BERBASIS ANDROID', Seman TIK, 2(1), pp. 65-74.

[3] Azwar, A. (2016) 'Rekayasa Kamus Bahasa Jepang - Indonesia Menggunakan Bahasa Pemrograman Java', Jurnal Edik Informatika, 2(1), pp. 144-151.

[4] Pangestika, G. V., Wikusna, W. and Hermansyah, A. (2017) 'Aplikas Pembelajaran Bahasa Inggris Untuk Murid Sekolah Dasar Berbasis Android', in e-Proceeding of Applied Science, pp. 1558-1575.

[5] Evayani and Ulfah, U. (2016) 'Perancangan Database Sistem Informasi Akuntansi Siklus Penjualan dengan Menggunakan Model REA (Studi Kasus pada PT Yudi Putra, Medan)', Jurnal Ilmiah Mahasiswa Ekonomi 
Akuntansi, 1(2), pp. 14.

[6] Setiyadi, A. and Harihayati, T. (2015) 'PENERAPAN SQLITE PADA APLIKASI PENGATURAN WAKTU UJIAN DAN PRESENTASI', Majalah Ilmiah UNIKOM, 13(2), pp. 221-226.

[7] Wahyu, D., Nugroho, A. P. and Puspitarini, E. W. (2016) 'GAME EDUKASI BERBASIS ANDROID SEBAGAI MEDIA PEMBELAJARAN UNTUK ANAK USIA DINI', Jurnal informatika Merdeka Pasuruan, 1(1),pp.46-58. 